\title{
Considerações acerca de dois casos de botulismo ocorridos no Estado da Bahia
}

\author{
Comments on two cases of botulism \\ in the State of Bahia, Brazil
}

\author{
Maria Aparecida Araújo Figueiredo', \\ Juarez Dias $^{2}$ e Rita Lucena ${ }^{3}$
}

\begin{abstract}
RESUMO
Relato de dois casos, incluindo um óbito, associados ao botulismo, onde houve dificuldade no diagnóstico da doença e falta de integração entre a vigilância sanitária e a vigilância epidemiológica. O objetivo é alertar profissionais para a seriedade deste agravo e refletir sobre as práticas de vigilância da saúde encontradas.
\end{abstract}

Palavras-chaves: Botulismo. Vigilância epidemiológica. Vigilância sanitária.

\begin{abstract}
A report on two cases of botulism, one fatal, in which disease diagnosis was difficult and collaboration between public health and epidemiological surveillance services was poor. The objective of this report is to warn professionals of the seriousness of this disease and to reflect on existing public health surveillance practices.
\end{abstract}

Key-words: Botulism. Epidemiological surveillance. Public health surveillance.

0 botulismo tem distribuição mundial. Acomete pessoas isoladas ou causa surtos familiares, geralmente relacionados à produção e a conservação dos alimentos. É considerado um problema de saúde pública devido a sua gravidade e alta letalidade.

Do latim botulus que significa embutido, o nome botulismo deve-se ao fato de no Século VIII esta doença ter sido associada ao consumo de embutidos ${ }^{4}$. Apesar de ainda ser considerada, pelo senso comum, como uma doença causada pelo consumo de embutidos ou enlatados, o botulismo pode acontecer, também, por contaminação de outros tipos de alimentos e por outras formas de contaminação. 0 Centers for Disease Control and Prevention (CDC) classifica o botulismo em quatro categorias epidemiológicas: a) botulismo por intoxicação alimentar; b) botulismo infantil; c) botulismo por lesão; d) botulismo indeterminado ${ }^{2}$.
É uma doença de início súbito, causada pela toxina de um bacilo anaeróbio denominado Clostridium botulinum. Atualmente são conhecidas oito variedades de toxinas botulínicas com características imunológicas distintas: A, B, C1, C2, D, E, F e G. Dentre essas, são patogênicas para o homem: as do tipo A, B, E e F. A evolução do quadro clínico está relacionada à quantidade de toxinas circulantes, e a letalidade se relaciona ao período de incubação: quanto mais curto, maior o risco de morte ${ }^{3}$.

A toxina botulínica atua sobre o sistema nervoso periférico bloqueando a transmissão neuromuscular, atingindo as membranas pré-sinápticas, onde atua impedindo a liberação da acetilcolina nas terminações nervosas, ocasionando a paralisia ${ }^{4}$.

Em todas as formas o quadro clínico é basicamente 0 mesmo. Inicialmente, os sinais e sintomas são gastrintestinais: náuseas, vômitos, diarréia e dor abdominal. 0 quadro neurológico se instala com manifestações de cefaléia, vertigem,

\footnotetext{
1. Universidade do Estado da Bahia e Secretaria de Saúde do Estado da Bahia, Salvador, BA. 2. Secretaria de Saúde do Estado da Bahia, Salvador, BA. 3. Universidade Federal da Bahia, Salvador, BA.

Endereço para correspondência: Dra. Maria Aparecida Araújo Figueiredo. Prédio do Centro de Atenção à Saúde Prof. José Maria de Magalhães Neto/DIVEP/SESAB. Av. ACM S/N, Iguatemi, 41820-000 Salvador, BA.

Tel: $55713270-5821 ; 5591730257$

e-mail:mfigueiredo@saude.ba.gov.br

Recebido para publicação em 10/2/2006

Aceito em 18/3/2006
} 
ptose palpebral, disartria, disfagia, paralisia facial bilateral, redução dos movimentos da língua e dificuldade para sustentar o pescoço. A paralisia se instala de modo descendente. Não há alteração do nível de consciência ${ }^{3}$.

Nos casos provocados por ingestão de alimentos, objeto deste relato, a doença tem manifestação súbita, podendo ocorrer em horas. Por ser grave, o botulismo requer, na maioria das vezes, tratamento em Unidade de Terapia Intensiva. 0 soro antibotulínico deve ser administrado o mais precocemente possível porque ele elimina a toxina circulante que ainda não se fixou no sistema nervoso ${ }^{3}$.

Apesar da gravidade, é uma doença pouco diagnosticada pelos profissionais de saúde. No Brasil, até julho de 2002, somente quinze casos foram notificados ${ }^{12}$. Este relato pretende descrever dois casos, ocorridos em duas cidades do interior da Bahia, cuja fonte provável de infecção foi um tipo de embutido fabricado no interior do Estado do Paraná e com ampla comercialização naqueles municípios.

\section{RELATO DOS CASOS}

0 primeiro ocorreu em uma criança de sete anos que chegou a um hospital do interior do estado com história de irritação ocular e ptose palpebral desde o dia anterior, apresentando edema e flacidez do pescoço, disfagia, lábios ressecados e língua esbranquiçada, sem febre. Foi medicada com penicilina benzatina de 1.200.000 UI intramuscular e dipirona gotas, sendo liberada a seguir. No terceiro dia, por não ter apresentado melhora do quadro, foi levada novamente ao hospital regional e, como não foi atendida, foi levada a uma clínica particular, onde foi diagnosticado traumatismo crânio-encefálico (TCE) grave, baseado em uma história prévia de queda da bicicleta há sete dias. Na ocasião, solicitou-se tomografia computadorizada e avaliação com neurocirurgião. De volta ao hospital regional, foi encaminhada à capital do estado com diagnóstico de TCE.

No hospital da capital, levantou-se a hipótese diagnóstica de botulismo e realizou-se exame de eletroneuromiografia que mostrou incremento da atividade de mais de $50 \%$ com estimulação repetitiva, confirmando um bloqueio pré-sináptico, padrão patognomônico com botulismo. Foram coletadas amostras de soro, lavado intestinal e raspado do ferimento. 0 exame bacteriológico do raspado do ferimento revelou pesquisa negativa para $C$. botulinum com conclusão satisfatória. 0 exame do lavado gástrico por bioensaio em camundongos revelou presença de toxina botulínica tipos A e B. 0 exame do lavado gástrico por bioensaio em camundongos revelou ausência de toxina botulínica. 0 caso foi notificado à secretaria estadual de saúde e, durante a investigação, foi coletada e enviada para análise bacteriológica, uma amostra do alimento consumido (embutido tipo chouriça) que ainda se encontrava na geladeira do domicílio da criança. o Laboratório Central do Estado (LACEN) informou à equipe de investigação a ocorrência de um caso semelhante, dois meses antes, com evolução para óbito, em outro município baiano, cuja história envolvia a ingestão do mesmo tipo de embutido do primeiro caso, produzido pelo mesmo fabricante.
0 segundo caso se referia a uma adolescente de 13 anos, com história de ingesta de embutido cru, tipo chouriça, às 20 horas do dia 25/11/2002. Apresentou sintomas da doença aproximadamente 12 horas depois: ptose bipalpebral, náuseas e vômitos. Tomou dipirona gotas e permaneceu no domicílio em companhia do irmão, acreditando ser um mal estar. À noite, cerca de 12 horas após o início dos sintomas, foi levada ao hospital municipal onde foi medicada e recebeu alta. No segundo dia de evolução, já apresentava dificuldade de respirar e flacidez de membros inferiores. Retornou ao hospital municipal onde foi internada. Foi medicada com Diazepan injetável, Voltaren $®$ injetável, Aminofilina injetável e um antiespasmódico. Como o quadro respiratório foi se agravando, o plantonista solicitou a transferência para Salvador, todavia, neste ínterim, a adolescente foi a óbito.

A vigilância sanitária municipal tomou conhecimento do caso no dia seguinte, fez apreensão cautelar de alimentos semelhantes no supermercado onde o alimento ingerido pela adolescente havia sido comprado e enviou uma amostra ao LACEN, porém, não informou à vigilância epidemiológica municipal, nem à vigilância epidemiológica estadual.

0 corpo foi para o Instituto Médico Legal (IML) de uma cidade vizinha. Na ocasião, a família chegou a suspeitar do alimento levando-o para ser examinado, contudo, foram informados, no IML, que não era necessário. o laudo do exame pericial atestou que as análises toxicológicas realizadas não detectaram presença das substâncias pesquisadas: psicotrópicos, incluindo cocaína, e inseticidas. Salienta-se que aquele IML não realiza exames bacteriológicos. A certidão de óbito atestou causa indeterminada.

A SESAB teve conhecimento desse caso através do LACEN, dois meses após o ocorrido. A família conservou na geladeira o alimento consumido pela adolescente até o dia da investigação realizada pelo nível central da SESAB (04/02/2003), que recolheu o alimento e o enviou ao LACEN. A amostra revelou estar imprópria para o consumo humano, por apresentar contaminação por estafilococos e clostrídios sulfito redutores. A análise do alimento em bioensaio em camundongo revelou ausência de toxina botulínica.

\section{DISCUSSÃo}

Clinicamente, é provável que o curso da doença e o prognóstico desses dois casos tenham variado quanto à gravidade em decorrência da quantidade de toxinas viáveis ingeridas: 0 primeiro ingeriu o alimento frito enquanto o segundo ingeriu 0 alimento cru. A toxina botulínica é termo-lábil ${ }^{2}$.

No tocante à assistência, em ambos os casos, foi clara a ausência do diagnóstico médico da doença. A incidência e a distribuição deste agravo não são precisas, devido principalmente, à subnotificação dos casos pelos profissionais de saúde que sequer suspeitam da doença ${ }^{13}$.

Em relação às ações de vigilância, a falta de integração entre a vigilância sanitária e a vigilância epidemiológica, ocorrida no nível municipal e entre o nível municipal e estadual, foi um ponto de estrangulamento grave para um processo de investigação, 
pois a vigilância sanitária do município teve conhecimento do caso e não notificou à vigilância epidemiológica (municipal ou estadual), em nenhum momento, mesmo sendo uma doença de notificação compulsória ${ }^{3}$ e de ter havido óbito.

Outro ponto de estrangulamento foi a ausência da interinstitucionalidade, tão necessária quando se trata de vigilância à saúde. Primeiro, porque não foi expressa a necessidade do encaminhamento do material para exame bacteriológico, uma vez que o IML não realiza este tipo de exame. Segundo, o mais grave, porque no Estado da Bahia não existe um sistema de vigilância de óbito (SVO) implantado, o que significa inexistência de um órgão que realize necropsias de interesse para a saúde pública. Vale ressaltar que os IML só são responsáveis por elucidar mortes de interesse jurídico.

Em relação ao encerramento dos casos, a eletroneuromiografia realizada no primeiro caso revelou um dado importante que foi o aumento do recrutamento muscular, após estimulação repetitiva com frequiência de mais de $50 \%$, que distingue o botulismo de outras doenças neuromusculares. Assim, este caso foi confirmado por critério clínico-laboratorial: eletroneuromiografia compatível com botulismo e isolamento da toxina alimentar no lavado gástrico.

0 segundo caso foi considerado confirmado segundo 0 critério de encerramento proposto pelo CENEPI quando há óbito: indivíduo que foi a óbito com quadro clínico compatível com botulismo, com confirmação clínico-epidemiológica 3 .

A guisa de conclusão é pertinente um convite à reflexão sobre as práticas de vigilância epidemiológica e de vigilância sanitária aqui encontradas. Independentemente das diversas concepções que se possa ter acerca da vigilância à saúde, é sempre necessário que as ações desenvolvidas tenham como preocupação o impacto sobre o estado de saúde da população através da diminuição e/ ou eliminação dos danos e riscos a que está exposta. Essa prática exige sempre ações integradas que transcendam os espaços institucionalizados dos serviços de saúde, expandindo-se para outros órgãos e setores ${ }^{6}$.

Por fim, espera-se que estas considerações também possam alertar os profissionais da assistência para a gravidade do não diagnóstico desse agravo de notificação compulsória e de alta letalidade no cotidiano dos serviços de saúde.

\section{REFERÊNCIAS BIBLIOGRÁFICAS}

1. Arap L, Pimentel EP, Piccolo RC. Surto de botulismo em conserva vegetal caseira, ocorrido no município de São Paulo em 1990. Higiene Alimentar 7: 32-4, 1993.

2. Ferreira MS, Nishioka SA, Almeida AB, Silveira PVP, Souza MC, Storti PC, Zenebon 0, Gelli DS, Souza A. Botulismo: considerações acerca de oito casos ocorridos no Triângulo Mineiro, Minas Gerais, Brasil. Revista Instituto Medicina Tropical São Paulo 29:137-141, 1987.

3. Fundação Nacional de Saúde. Guia de vigilância epidemiológica. $5^{\text {a }}$ edição FUNASA, Ministério da Saúde, Brasília, 2002.

4. Junqueira VCA, Serrano AM. Clostridium botulinum: cronologia das descobertas, caracterização, manifestações clínicas, diagnóstico e controle. Coletânea Instituto Tecnologia Alimentos 24: 29-39,1994.

5. Moline NM, Kemeny TG, Ferreiro EA. Botulismo en una lactante. Revista Chilena Pediatria 67: 10-12, 1996.

6. Teixeira CF, Paim JS, Vilasbôas AL. SUS, modelos assistenciais e vigilância da saúde. Informe epidemiológico do SUS. Fundação Nacional de Saúde, Brasília, 1998. 